\title{
Increased Number of Human Cases of Influenza Virus A(H5N1) Infection, Egypt, 2014-15
}

\author{
Samir Refaey, Eduardo Azziz-Baumgartner, \\ Marwa Mohamed Amin, Manal Fahim, \\ Katherine Roguski, \\ Hanaa Abu Elsood Abd Elaziz, A. Danielle luliano, \\ Noha Salah, Timothy M. Uyeki, \\ Steven Lindstrom, Charles Todd Davis, Alaa Eid, \\ Mohamed Genedy, Amr Kandeel
}

During November 2014-April 2015, a total of 165 case-patients with influenza virus $A(H 5 N 1)$ infection, including 6 clusters and 51 deaths, were identified in Egypt. Among infected persons, $99 \%$ reported poultry exposure: $19 \%$ to ill poultry and $35 \%$ to dead poultry. Only 1 person reported wearing personal protective equipment while working with poultry.

$\mathrm{H}$ ighly pathogenic avian influenza virus $\mathrm{A}(\mathrm{H} 5 \mathrm{~N} 1)$ has been detected among poultry in $>60$ countries, with sporadic transmission to humans that results in a large number of deaths (1). Of 842 persons with $\mathrm{H} 5 \mathrm{~N} 1$ virus infection reported as of June 23, 2015, worldwide, 447 (53\%) died (2,3). During November 2014-February 2015, the Egyptian Ministry of Health $(\mathrm{MoH})$ surveillance systems identified an unprecedented number of persons with severe respiratory illness caused by infection with $\mathrm{H} 5 \mathrm{~N} 1$ virus. These illnesses occurred during months when seasonal influenza is typically epidemic in Egypt (4). In response, the $\mathrm{MoH}$ initiated an investigation into potential causes of the increased number of cases.

\section{The Study}

Since 2006, MoH mandates that clinicians refer all persons with influenza-like illness (ILI) and $\leq 2$-week history of poultry contact to 1 of $\approx 83$ Chest and Fever hospitals (i.e., a category of referral hospitals) throughout Egypt (online Technical Appendix Figure, http://wwwnc.cdc. gov/EID/article/21/12/15-0885-Techapp.pdf). Persons meeting the ILI case definition have fever $\geq 38^{\circ} \mathrm{C}$ and $\geq 1$ of the following: cough, dyspnea, sore throat, myalgia, and body aches. Persons meeting the ILI case definition

Author affiliations: Egyptian Ministry of Health, Cairo, Egypt

(S. Refaey, M.M. Amin, M. Fahim, H.A.E.A. Elaziz, N. Salah,

A. Eid, M. Genedy, A. Kandeel); Centers for Disease Control and Prevention, Atlanta, Georgia, USA (E. Azziz-Baumgartner, K. Roguski, A.D. Iuliano, T.M. Uyeki, S. Lindstrom, C.T. Davis)

DOI: http://dx.doi.org/10.3201/eid2112.150885 are admitted, and respiratory samples are collected for influenza testing.

Technicians at 8 sentinel sites also collected daily respiratory samples from 2 patients meeting the ILI case definition and from all patients admitted with severe acute respiratory infection, defined as hospitalization occurring within 2 weeks of onset of fever and cough. Nasal and oropharyngeal swabs were transported to Egypt's National Influenza Center for testing by reverse transcription PCR (2). For patients testing positive for $\mathrm{H} 5 \mathrm{~N} 1, \mathrm{MoH}$ staff visited their households; administered a standardized questionnaire to obtain demographic, exposure, clinical, and treatment information; and searched among patient contacts for additional case-patients.

We obtained surveillance data collected during 20062015 and compared case-patients with H5N1 virus infection for November 2014-April 2015 to those reported in previous years. We obtained the average epidemic period by calculating the proportion of samples testing positive for $\mathrm{H} 5 \mathrm{~N} 1$ each month throughout the period (4). An epidemic was defined as consecutive months having a proportion of $\mathrm{H} 5 \mathrm{~N} 1$-positive samples that exceeded the annual July-June median.

During March 20, 2006-April 20, 2015, a total of 342 persons with H5N1 virus infection were identified in Egypt (Figure). Annual epidemics typically occurred during November-April, when 299 (87\%; 95\% CI 84\%-91\%) of the $342 \mathrm{H} 5 \mathrm{~N} 1$ illnesses occurred, resulting in a median of 23 case-patients (interquartile range [IQR] 13-31) per epidemic. Of the total 342 case-patients, 165 were identified during 2014-15, including 6 clusters of 2-3 case-patients. Although this season had a higher number of case-patients than previous years, other seasons had higher proportions of $\mathrm{H} 5 \mathrm{~N} 1$ detections or clusters among samples tested. The median percentage $(5.4 \%)$ of monthly $\mathrm{H} 5 \mathrm{~N} 1$ detections among humans sampled during November 2014-April 2015 was statistically similar to the median percentage (2.9\%) for March 2006-October 2014 (Kruskal-Wallis test; $p=0.5$ ). The proportion of clustered case-patients was also similar for the 2 periods: $12(7.3 \%$; 95\% CI $3.3 \%-$ $11.2 \%)$ of 165 case-patients during $2014-15$ and 12 (6.8\%; 95\% CI 3.1-10.5) of 177 case-patients during 2006-2014. The number of human H5N1 case-patients identified each month was highly correlated with the number of $\mathrm{H} 5 \mathrm{~N} 1$ poultry outbreaks identified each month during 2006-2015 by the Ministry of Agriculture in the same communities $(\mathrm{R}=0.3, \mathrm{p}=0.002)$. 


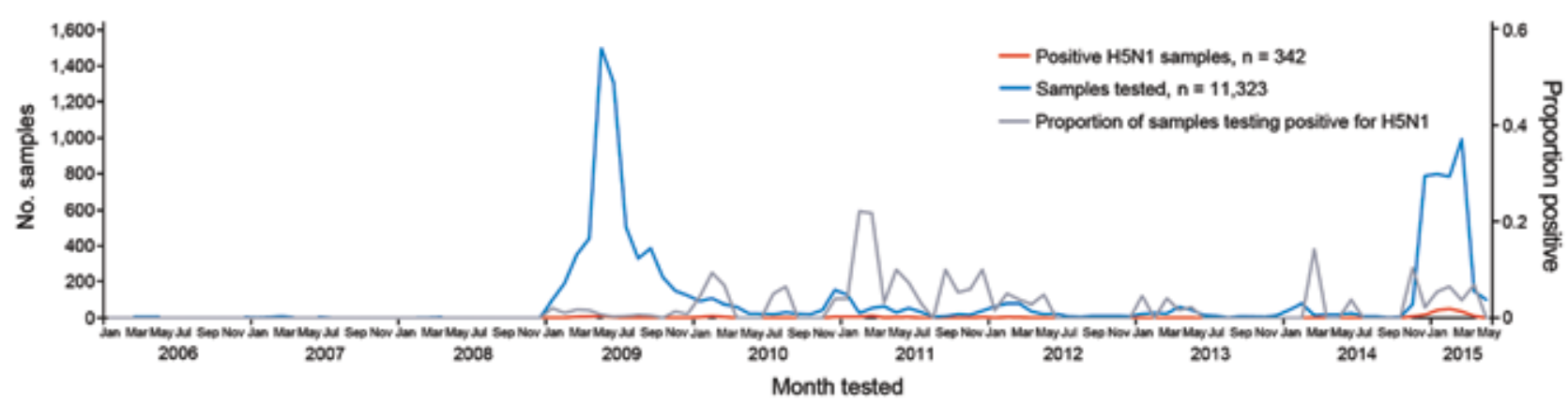

Figure. Number of human respiratory samples tested, number of samples testing positive for influenza virus $A(H 5 N 1)$, and proportion of positive samples, Egypt, March 2006-May 2015.

The case-patients identified during 2014-15 were characteristically similar to those from previous seasons. Similar percentages were found to be women (100/165 [61\%] for 2014-15; 105/177 [59\%] for 2006-2014), homemakers (50/164 [30\%] for 2014-15; 46/177 [26\%] for 2006-2014), and poultry farm workers $(2 / 165[1 \%]$ for $2014-15$; 0 for 2006-2014). Case fatality rates were also similar: 51 (31\%) deaths among 165 case-patients during 2014-15 versus 64 deaths (36\%) among 177 case-patients for March 2006October $2014(\mathrm{p}=0.3)$.

Almost all (163/165) case-patients during 2014-15 had exposure to domestic poultry 1-2 weeks before symptom onset; $58 \%$ were involved in breeding, $24 \%$ in slaughtering, and $21 \%$ in preparing poultry. Most (115/165 [70\%]) were exposed at home; $4 \%$ recalled exposure in shops, $3 \%$ at live bird markets, and $1 \%$ at farms. Although 35\% recalled exposure to dead birds and 19\% to ill birds, $35 \%$ recalled exposure only to birds that appeared healthy. One case-patient reported wearing personal protective equipment when working with poultry.

Case-patients identified in 2014-15 were admitted and received oseltamivir treatment a median of 4 (IQR 2-7) days after symptom onset. Sixteen percent had preexisting medical conditions: 8 (5\%; 95\% CI $2 \%-8 \%)$ had chronic chest illnesses; 5 (3\%; 95\% CI 0.3\%-6\%) had cardiovascular disease; 5 (3\%; 95\% CI 0.3\%-6\%) had diabetes; 2 (1\%; $95 \%$ CI $0 \%-3 \%)$ had renal failure; $2(0.1 \%$; $95 \%$ CI $0 \%-$ $3 \%)$ had liver failure; and $1(0.6 \%$; $95 \%$ CI $0 \%-2 \%)$ was obese. In addition, $9(10 \%$; $95 \%$ CI $4 \%-16 \%)$ of 92 women 15-49 years of age were pregnant. Most case-patients had cough (87\%) and dyspnea (72\%) during their illness.

As of July 2015, of the 165 case-patients, 114 (69\%) had survived and 51 (31\%) died. Survivors were younger than decedents (median age 16 [IQR 3-36] vs. 33 [IQR 20-43] years; $p=0.0001$ ). Oseltamivir treatment was begun within a median 4 (IQR 2-6) days of symptom onset for survivors, compared with a median 5 (IQR 3-7) days for decedents (2-sided Wilcoxon rank-sum test; $\mathrm{p}=0.07$ ).

\section{Conclusions}

Our analyses suggest that $\mathrm{H} 5 \mathrm{~N} 1$ infections have recurred annually in Egypt during November-April. Although $\mathrm{MoH}$ identified an unprecedented number of $\mathrm{H} 5 \mathrm{~N} 1$ case-patients during 2014-15, the proportion of persons testing positive was similar to proportions of previous epidemic seasons. During 2006-2015, the Ministry of Agriculture identified 3,273 outbreaks among poultry, primarily during Egypt's November-April winter months (1). One study found that $\approx 2 \%$ of Egyptians exposed to poultry were seropositive for $\mathrm{H} 5 \mathrm{~N} 1$ virus (5). The large number of H5N1 case-patients identified during 2014-15 could result in part from increased respiratory sampling in communities with poultry outbreaks, rather than from marked changes in the virus's transmission characteristics.

The H5N1 case-patients during the 2014-15 season had similar characteristics to those of previous seasons (6). Nearly all had recent exposure to domestic poultry (7). Active surveillance from 2010-2012 suggests that 8\% of healthy-appearing poultry in Egypt were infected with H5N1 clade 2.2.1 (8), yet only 1 case-patient in 2014-15 reported using personal protective equipment.

Human H5N1 infections have been shown to occur during poultry outbreaks, overlapping with October-December influenza epidemics (4). Egypt currently recommends seasonal influenza vaccination among health care workers, pregnant women, persons with chronic diseases, and Hajj and Umrah travelers. Countries where seasonal influenza overlaps with $\mathrm{H} 5 \mathrm{~N} 1$ circulation in poultry might explore the feasibility of vaccinating persons at high risk for influenza co-infections and complications (9).

After identification of case-patients in Egypt, officials investigated contacts. This strategy perhaps enriched the number of $\mathrm{H} 5 \mathrm{~N} 1$ case-patients identified during peak epidemic months, compared with randomly selecting persons meeting case definitions for respiratory illnesses. Although we did not find increased rates of persons testing positive for $\mathrm{H} 5 \mathrm{~N} 1$, all $\mathrm{H} 5 \mathrm{~N} 1$ case-patients are unlikely to have the 
same probability of being identified (i.e., contacts vs. randomly selected persons).

Egypt continues to have substantial H5N1 circulation among poultry. Although the characteristics of case-patients during 2014-15 were similar to those of previous seasons and do not suggest increased efficiency of H5N1 transmission between humans, $\mathrm{MOH}$ would be warranted in examining H5N1 virus circulating in Egypt for genomic markers of mammalian adaptation (10), which have been identified since 2010 (11), and in using a cross-sectoral approach to evaluate interventions to prevent $\mathrm{H} 5 \mathrm{~N} 1$ infections.

\section{Acknowledgments}

We thank Ann Moen, Joseph Bresee, and Margaret McCarron for their assistance through the Ministry of Health-Centers for Disease Control and Prevention cooperative agreement; Emad Mohareb, Mary Younan, Marc Wooster, and Patrick Blair for their assistance with outbreak response; and Mark Thompson and Jerome Tokars for their review of the manuscript. We also thank Egypt's Epidemiology and Surveillance Unit staff (Ibrahim Saeed, Mahmoud Hassan, Ahmed Helmy, Fatma Shahat, El-Sabah Ali, and Mohamed Kamal); the Field Epidemiology Training Program staff and fellows (Sahar Samy, Eman Hamed, Reham AbdelMohaymen, and Mahmoud Taha); and the Communicable Disease Control Department staff (Doaa Zahran, Mohamed Shabaan, Mohamed Attia, and Mohamed Daif).

The surveillance systems that yielded data for this investigation were partially funded through the Centers for Disease Control and Prevention cooperative agreement CDC-RFA-IP0990204CONT12.

Dr. Refaey is the Director of Epidemiology and Disease Surveillance and Field Epidemiology Training Program at the Egyptian Ministry of Health, where he leads influenza surveillance, outbreak response, and prevention and control.

\section{References}

1. Durand LO, Glew P, Gross D, Kasper M, Trock S, Kim IK, et al. Timing of influenza $\mathrm{A}(\mathrm{H} 5 \mathrm{~N} 1)$ in poultry and humans and seasonal influenza activity worldwide, 2004-2013. Emerg Infect Dis. 2015;21:202-8. http://dx.doi.org/10.3201/eid2102.140877
2. World Health Organization. Recommendations and laboratory procedures for detection of avian influenza $\mathrm{A}(\mathrm{H} 5 \mathrm{~N} 1)$ virus in specimens from suspected human cases. Geneva: The Organization; 2007 Aug [cited 2015 Mar 18]. http://www.who.int/influenza/ resources/documents/RecAIlabtestsAug07.pdf

3. World Health Organization. Influenza at the human-animal interface. summary and assessment as of 23 June 2015. Geneva: The Organization; 2015 [cited 2015 July 16]. http://www.who.int/ influenza/human_animal_interface/Influenza_Summary_IRA_HA_ interface 23 June 2015.pdf?ua $=1$

4. Azziz Baumgartner E, Dao CN, Nasreen S, Bhuiyan MU, Mah-E-Muneer S, Al Mamun A, et al. Seasonality, timing, and climate drivers of influenza activity worldwide. J Infect Dis. 2012;206:838-46. http://dx.doi.org/10.1093/infdis/jis467

5. Gomaa MR, Kayed AS, Elabd MA, Zeid DA, Zaki SA, El Rifay AS, et al. Avian influenza A(H5N1) and A(H9N2) seroprevalence and risk factors for infection among Egyptians: a prospective, controlled seroepidemiological study. J Infect Dis. 2015;211:1399-407. http://dx.doi.org/10.1093/infdis/jiu529

6. Lohiniva AL, Dueger E, Talaat M, Refaey S, Zaki A, Chisholm HK, et al. Poultry rearing and slaughtering practices in rural Egypt: an exploration of risk factors for $\mathrm{H} 5 \mathrm{~N} 1$ virus human transmission. Influenza Other Respir Viruses. 2013;7:1251-9. http://dx.doi.org/ 10.1111/irv. 12023

7. Kandeel A, Manoncourt S, Abd el Kareem E, Mohamed Ahmed AN, El-Refaie S, Essmat H, et al. Zoonotic transmission of avian influenza virus (H5N1), Egypt, 2006-2009. Emerg Infect Dis. 2010;16:1101-7. http://dx.doi.org/10.3201/ eid1607.091695

8. Kayali G, Kandeil A, El-Shesheny R, Kayed AS, Gomaa MM, Maatouq AM, et al. Active surveillance for avian influenza virus, Egypt, 2010-2012. Emerg Infect Dis. 2014;20:542-51. http://dx.doi.org/10.3201/eid2004.131295

9. World Health Organization. SAGE meetings. Geneva: The Organization; 2015 [cited 2015 Feb 2]. http://www.who.int/ influenza/vaccines/SAGE_information/en/

10. Arafa AS, Naquib MM, Luttermann C, Selim AA, Kilany WH, Hagag N, et al. Emergence of a novel cluster of influenza A(H5N1) virus clade 2.2.1.2 with putative human health impact in Egypt, 2014/2015. Euro Surveill. 2015;20:2-8.

11. El-Shesheny R, Kandeil A, Baqato O, Maatouq AM, Moatasim Y, Rubrum A, et al. Molecular characterization of avian influenza H5N1 virus in Egypt and the emergence of a novel endemic subclade. J Gen Virol. 2014;95:1444-63. http://dx.doi.org/10.1099/vir.0.063495-0

Address for correspondence: Eduardo Azziz-Baumgartner, Centers for Disease Control and Prevention, 1600 Clifton Rd NE, Mailstop A32, Atlanta, GA 30329-4027, USA; email: eha9@cdc.gov

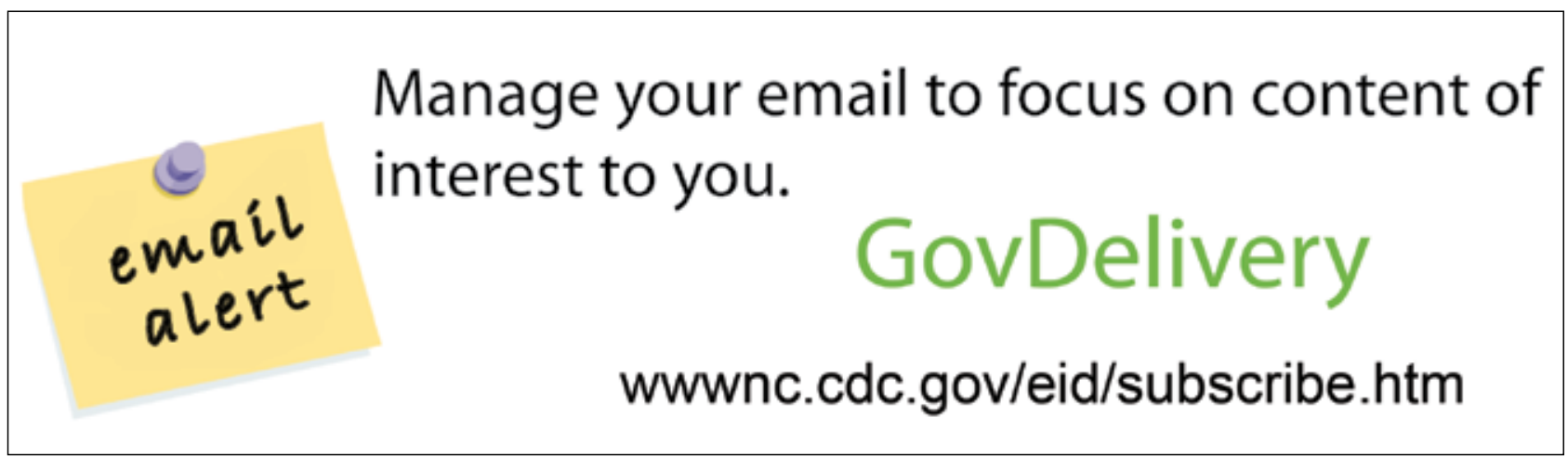

